\title{
Influence of Periodontal Disease on Changes of Glycated Hemoglobin Levels in Patients With Type 2 Diabetes Mellitus: A Retrospective Cohort Study
}

Katia L. Costa, ${ }^{*}$ Zuila A. Taboza, ${ }^{*}$ Gisele B. Angelino, ${ }^{\dagger}$ Virginia R. Silveira, ${ }^{\dagger}$ Renan Montenegro Jr. ${ }^{\ddagger}$ Alex N. Haas, ${ }^{\S}$ and Rodrigo O. Rego*†

Background: Little evidence is available regarding the effects of long-term periodontal infection on diabetes mellitus (DM) control. The aim of this retrospective cohort study is to evaluate influence of periodontal status on changes of glycated hemoglobin (HbA1c) levels of patients with type 2 DM (DMt2).

Methods: Eighty patients (mean age: $56.0 \pm 8.9$ years) with DMt2 were included. Patients were non-smokers, aged $\geq 40$ years, and using antidiabetic drugs. Demographics, health history, and HbA1c levels were retrieved from medical charts. Probing depth and clinical attachment loss (AL) were recorded.

Results: Patients were examined at two time points within a mean interval of $38.6 \pm 6.6$ months. Increase in HbA1c over time was statistically significant when severe periodontitis was diagnosed at baseline $(2.32 \%, 95 \%$ confidence interval [CI]: $1.50 \%$ to $3.15 \%$ ), in patients showing at least one tooth with $\geq 2 \mathrm{~mm}$ of $\mathrm{AL}$ progression $(2.24 \%, 95 \% \mathrm{Cl}: 1.56 \%$ to $2.91 \%)$, in males $(2.75 \%, 95 \% \mathrm{CI}: 1.72 \%$ to $3.78 \%)$, and in those with $\mathrm{HbA} 1 \mathrm{c}<6.5 \%$ at baseline $(3.08 \%, 95 \% \mathrm{CI}: 2.47 \%$ to $3.69 \%)$. After adjusting for baseline $\mathrm{HbA} 1 \mathrm{c}$, significant changes were still observed for severe periodontitis and progression of AL with increases of $0.85 \%$ and $0.9 \%$, respectively. After adjusting for sex and $\mathrm{HbA1c}$, AL progression was also statistically significant, with increases of $0.84 \%$.

Conclusions: Periodontitis progression was associated with increase in $\mathrm{HbA} 1 \mathrm{c}$ in patients with DMt2. Identification of these risk factors suggests that periodontal treatment may improve glycemic control of patients with DMt2 by eliminating periodontal infection. J Periodontol 2017;88:17-25.

\section{KEY WORDS}

Diabetes mellitus, type 2; hyperglycemia; periodontitis.

\footnotetext{
* Department of Clincal Dentistry, Graduate Program in Dentistry, Faculty of Pharmacy Dentistry and Nursing, Federal University of Ceara, Fortaleza, Brazil.

† Department of Dentistry, School of Dentistry, Federal University of Ceara, Sobral, Brazil.

‡ Department of Community Health, Faculty of Medicine, Federal University of Ceara, Fortaleza.

$\S$ Department of Conservative Dentistry, School of Dentistry, Federal University of Rio Grande do Sul, Porto Alegre, Brazil.
}

$\mathrm{D}$ iabetes mellitus (DM) and its complications are some of the most significant and rising chronic health problems in the world, affecting around 415 million people. ${ }^{1}$ Approximately $90 \%$ of these individuals present with type 2 DM (DMt2). ${ }^{1}$ In Europe 59.8 million adults have DM, including 23.5 undiagnosed cases. ${ }^{1}$ In the United States, it is estimated that there were 22 million people diagnosed with DM in $2014 .^{2}$ According to estimates of the latest census, in Brazil $>9$ million adults were affected, representing $4.5 \%$ of the population. ${ }^{3} \mathrm{DM}$ has been associated with periodontitis, ${ }^{4}$ and the higher the blood glucose levels, the more likely that patients with DM develop periodontitis compared with individuals without DM. ${ }^{5}$ On the other hand, the inflammatory process associated with periodontitis can interfere with glycemic control in DMt2 as patients with DM showed a decrease of $0.3 \%^{6}$ to $0.4 \%^{7}$ for glycated hemoglobin (HbA1c) levels after periodontal treatment.

Some possible mechanisms to support this hypothesis have been recently reviewed. ${ }^{8}$ Inflammatory cytokines, such as interleukin (IL)-1 $\beta$ and IL-6, and the ratio between nuclear factor-kappa B receptor ligand and osteoprotegerin are elevated in patients with DM and periodontitis compared with those only presenting with periodontitis. ${ }^{8}$ DM-associated hyperglycemia leads to alterations in hemostasis 
of alveolar bone and formation of advanced glycation end products, which play a proinflammatory and prooxidative role in cells. ${ }^{8}$ Periodontal infection potentiates the vicious cycle in DM, leading to faster periodontal destruction. In contrast, supporting the bidirectional relationship of both diseases, it is suggested that elevated levels of C-reactive protein, IL-6, and tumor necrosis factor-alpha expressed during periodontal disease can negatively interfere with glycemic control. ${ }^{8}$

A meta-analysis of observational studies, including 47 cross-sectional and eight cohort studies, revealed that DMt2 is a risk factor for periodontal disease, with patients with DMt2 presenting greater clinical attachment loss (AL) compared with patients without DMt2. ${ }^{4}$ However, only some studies are available that have evaluated the effect of periodontitis on glycemic control in patients with DMt2. ${ }^{9-17}$ Ide et al. ${ }^{11}$ evaluated 5,948 Japanese patients with moderate and severe periodontitis as well as healthy periodontal status for 7 years and observed significant association between moderate and severe periodontitis and increased risk for DMt2. When results were adjusted for confounding factors such as triglycerides, a decrease in this association was noted. ${ }^{11}$ Evaluating Pima Indians with DMt2, in a 2-year follow-up, Taylor et al. ${ }^{12}$ observed a relationship between severe periodontitis at baseline and increased risk for greater uncontrolled glycemic status. Saremi et al. ${ }^{13}$ found that, after adjusting for age, sex, DMt2 duration, hypertension, and smoking, risk for cardiorenal mortality increased by 3.2 times in patients with severe periodontitis compared with patients presenting with healthy periodontal status or slight-to-moderate periodontitis. In a 22-year longitudinal study on the effects of periodontitis on onset of nephropathy and end-stage renal disease, Shultis et al. ${ }^{14}$ observed that periodontitis is a predictor for development of both conditions in patients with DMt2. These cohort studies are relevant owing to longitudinal evaluation of both diseases and can help determine the order in which they occur. Demmer et al. ${ }^{15}$ followed patients without DM with periodontitis for 5 years and observed an increase in glycemic levels of these patients. The same research group found baseline periodontal disease to be clinically relevant and a predictor of incident DMt2 in a population-based sample representative of adults in the United States. ${ }^{16}$

Studies have reported incidence and progression of periodontal disease in patients with DMt2 in Brazil; ${ }^{18-20}$ however, none of them evaluated the effects of chronic periodontal disease progression on DM outcomes. It is deemed important to evaluate patients from a specific geographic area with low socioeconomic and educational status who receive medical treatment from the public health care system, in which the majority of patients with DM and those presenting periodontal disease seek treatment. ${ }^{21}$ These factors can also be evaluated as risk determinants of the association between these conditions.
Therefore, the aim of this cohort study is to associate periodontal status at baseline and progression of periodontal disease with changes in HbA1c levels in patients with DMt2.

\section{MATERIALS AND METHODS}

This cohort study was conducted with 80 patients with DM (27 males and 53 females, aged 40 to 74 years; mean age: $56.0 \pm 8.9$ years at baseline) attending primary health care units from a northeastern city (Sobral, Ceara) in Brazil. Study protocol was approved by the Ethics Committee of the State University of Acarau Valley, Sobral, Ceara, Brazil. Due to the retrospective nature of this study, exemption of written consents of participants was granted by the Ethics Committee.

To be included in the study patients had to fulfill the following inclusion criteria during baseline and final assessments: 1) controlled or uncontrolled DMt2; 2) at least six teeth; 3) non-smokers; 4) aged $\geq 40$ years; and 5 ) use of antidiabetic medication (i.e., metformin, glibenclamide, or insulin). Patients excluded from the study included those who: 1) were bedridden during follow-up period; 2 ) received scaling and root planing; 3 ) did not present medical records of blood analysis at follow-up; 4) refused to participate; 5) died; and 6) had changed address or could not be contacted.

Baseline recruitment was conducted from January to September 2008 at the School of Dentistry, Federal University of Ceara, Sobral, Brazil. ${ }^{22}$ Figure 1 is a flowchart of the present study sample. A total of 595 patients were screened for eligibility, and 185 were examined at baseline. After at least 24 months, 80 were included and analyzed.

\section{Study Power}

Baseline sample size to ensure adequate power for association between periodontal disease status and DM control was calculated considering data previously published, ${ }^{23-25}$ and it was estimated that 170 to 210 patients would be needed to provide $80 \%$ power with $\alpha=$ 0.05 . For the present follow-up analysis, power calculation was performed for multivariable linear regression models applied in this study, considering $\mathrm{n}=80, R^{2}=$ 0.20 , and $\alpha$ and $\beta$ errors of $5 \%$ and $20 \%$, respectively. Taking into account a model with up to four independent variables, it was estimated that the present sample yields $97 \%$ power to find significant association between any periodontal parameter and changes in HbA1c levels.

\section{Clinical Procedures}

Full-mouth periodontal examination was performed at baseline and at follow-up examination with a 15-mm periodontal probe.l Periodontal probing depth (PD) was measured in six sites per tooth (mesio-buccal, buccal,

|| UNC-15, Trinity Industry and Trade, Sao Paulo, SP, Brazil. 


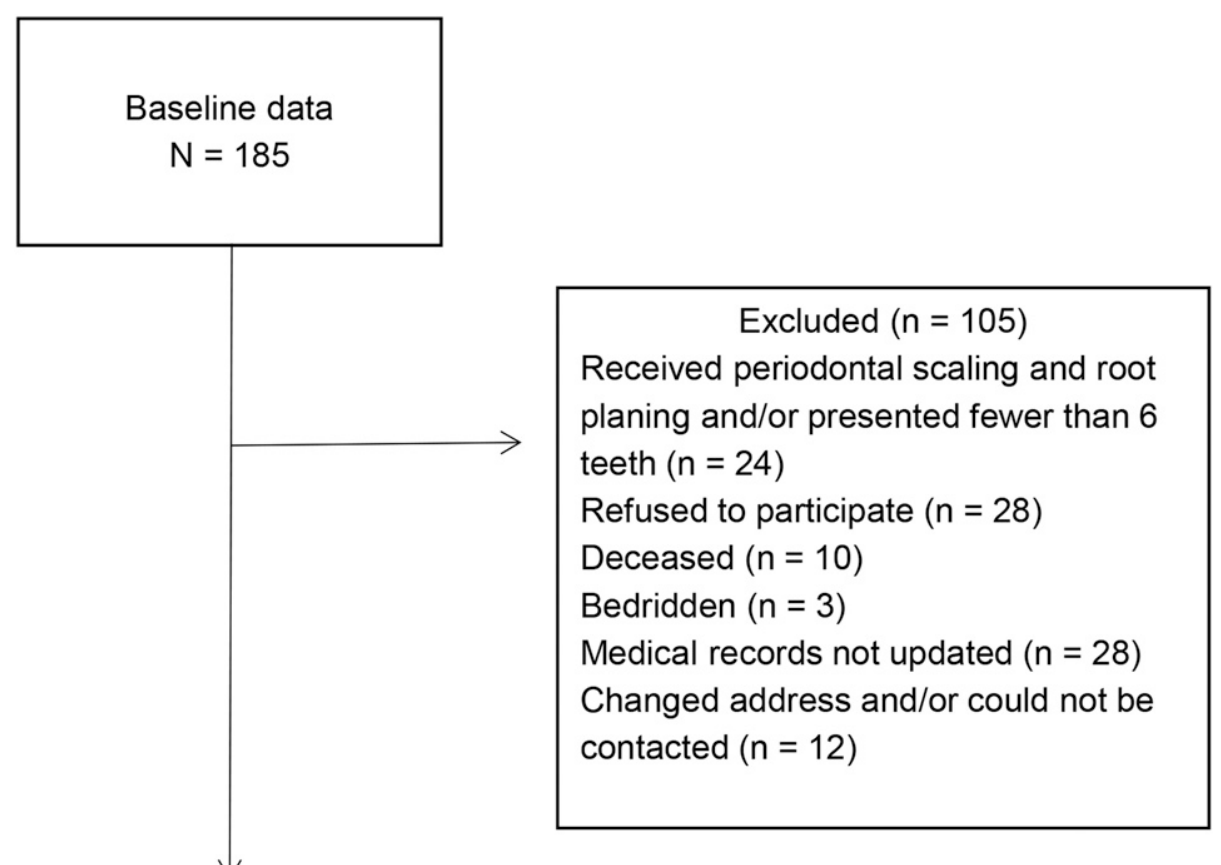

Analyzed

$(\mathrm{n}=80)$

Sobral, Ceara, Brazil. All tests were done using an ion-exchange highperformance liquid chromatography method"l at the Public Health Laboratory, Sobral, Ceara, Brazil.

\section{Study Outcomes}

Primary outcome of the present study was glycemic control using change in HbA1c levels over the follow-up period. A cut off point of $<6.5 \%$ was used. ${ }^{26}$ Periodontal disease was the main exposure of the study. Other independent variables considered as possible confounders included: 1) age; 2) sex; 3) time of DM; 4) use of antidiabetic drugs; and 4) baseline HbA1c.

Periodontal disease was analyzed using two descriptors that were calculated considering only the worst site of each tooth and were further associated with changes in HbA1c levels in separate models. Individuals were dichotomized into those having or not having severe periodontitis according to criteria from the Centers for Disease Control and Prevention $(C D C)$ and the

disto-buccal, mesio-lingual, lingual, and disto-lingual) in all present teeth excluding third molars. Gingival recession (GR) was measured in sites where the gingival margin was located apical to the cemento-enamel junction. Clinical AL was calculated for these sites as the sum of PD and GR. Number of missing teeth and number of teeth with records for AL were registered. Teeth that were lost during the follow-up period were excluded from analyses.

\section{Periodontal Reliability}

One experienced periodontist (KC), previously calibrated, performed all examinations. Repeated measurements of PD were performed in 12 patients at baseline and follow-up. Intraclass correlation coefficients of agreement for PD were 0.91 and 0.93, respectively.

\section{Medical Data}

Medical and laboratory information were retrieved by two researchers (ZT and GA) from the patient charts. Medical information was collected from the closest visit to the periodontal examination (a maximum period of 1 month among them). Information regarding DM status and medication was recorded.

HbA1c levels were retrieved from medical charts of patients from the City Public Health Department,
American Academy of Periodontology (AAP), 27 in which severe periodontitis is determined when $\geq 2$ interproximal sites have AL $>6 \mathrm{~mm}$ (not in the same tooth) and $\geq 1$ interproximal sites have PD $\geq 5 \mathrm{~mm}$. To measure the effect of periodontal deterioration over time on changes in HbA1c levels, individuals were dichotomized into progressive and non-progressive cases considering a cut off point of $2 \mathrm{~mm}$ of $\mathrm{AL}$ progression in at least one tooth.

\section{Statistical Analyses}

Baseline level of HbA1c and its change over time were compared across categories for each independent variable using independent samples $t$ test. Association between changes in glycemic control and periodontal parameters were evaluated using linear regression models. Multivariable models were fitted using a purposeful approach. ${ }^{28}$ Univariable models were fitted, and variables presenting $P<0.20$ were entered in a multivariable model. After analysis of confounding, interactions, and $P<0.05$, it was found that sex and baseline $\mathrm{HbA} 1 \mathrm{c}$ were significant predictors for change in HbA1c levels. Two separate analyses were conducted for baseline severe periodontitis and

If Katal Biotechnology Industry and Trade Ltd., Sao Paulo, SP, Brazil. 
progression of $\mathrm{AL} \geq 2 \mathrm{~mm}$, adjusting for sex and baseline HbA1c. Significance level was set at $P=0.05$ for all analyses. ${ }^{\#}$

\section{RESULTS}

Mean follow-up time was $38.6 \pm 6.6$ months. The majority of patients were women. Mean age of the sample was 56 years (Table 1). Mean baseline concentration of $\mathrm{HbA} 1 \mathrm{c}$ was $7.0 \%$, and 37 (46.2\%) patients had controlled DM at the beginning of the study, with mean time of DM of 6.5 years. Mean PD and AL were 3.2 and $5.1 \mathrm{~mm}$, respectively. Thirty patients $(37.5 \%)$ had severe periodontitis at baseline. Despite the fact that all included patients did not receive periodontal treatment over the study period, 34 patients had lost at least one tooth (16 patients lost one tooth, 11 patients lost two teeth, and seven patients lost three to six teeth).

Table 2 shows baseline concentrations of HbA1c and its change over time according to independent variables. Females and those presenting $>5$ years of DM had significantly higher baseline levels of HbA1c. Also, patients with uncontrolled DM $(\geq 6.5 \%)$ had significantly higher baseline levels of HbA1c compared with patients with controlled DM $(<6.5 \%)$, as expected. There was significant difference $(P=0.001)$ for duration of DM between patients with uncontrolled (7.5 \pm 0.7 years $)$ and those with controlled DM ( $5.5 \pm 0.6$ years $)$ at

\section{Table I.}

\section{Characteristics of Study Patients at Baseline}

\begin{tabular}{lc}
\hline Characteristics & Values \\
\hline Age (years), mean \pm SD & $56.0 \pm 8.9$ \\
Females, $n(\%)$ & $53(66.2)$ \\
HbAlc (\%), mean \pm SD & $7.0 \pm 1.7$ \\
$<6.5 \%, n(\%)$ & $37(46.2)$ \\
$>6.5 \%, n(\%)$ & $43(53.8)$ \\
Duration of DM (years), mean \pm SD & $6.5 \pm 4.2$ \\
Time between exams (months), mean \pm SD & $38.6 \pm 6.6$ \\
Tooth count, mean \pm SD & $14.9 \pm 6.2$ \\
Tooth count with AL, mean \pm SD & $6.3 \pm 4.4$ \\
PD* (mm), mean \pm SD & $3.2 \pm 1.0$ \\
AL* (mm), mean \pm SD & $5.1 \pm 1.5$ \\
Periodontal condition & \\
Healthy/mild periodontitis, $n(\%)$ & $16(20.0)$ \\
Moderate periodontitis, $n(\%)$ & $34(42.5)$ \\
Severe periodontitis, $n(\%)$ & $30(37.5)$ \\
\hline
\end{tabular}

* Considering the worst site of each tooth. baseline, without significant differences between them regarding age, $56.2 \pm 9.3$ and $55.9 \pm 8.7$ years, respectively (data not shown). No other significant differences were observed for baseline values of $\mathrm{HbA1c}$, including for two periodontal variables and tooth loss over time. Changes in HbA1c levels over time were significantly higher in patients with severe periodontitis at baseline $(2.32 \%)$ than in those without it. Similarly, levels of $\mathrm{HbA} 1 \mathrm{c}$ had a significantly higher increase in patients presenting AL progression (2.24\%) than in patients with no AL progression. Increase in $\mathrm{HbA} 1 \mathrm{c}$ was also higher in males $(2.75 \%)$ than in females, and in patients with controlled (3.08\%) versus uncontrolled DM. Significant differences were not observed for age or duration of DM.

Association between periodontal status and changes in $\mathrm{HbA} 1 \mathrm{c}$ is shown in Table 3 . In multivariate model 1, adjusted for baseline $\mathrm{HbA} 1 \mathrm{c}$, presence of severe periodontitis at baseline and progression of AL were significantly associated with increases in $\mathrm{HbA} 1 \mathrm{c}$ of $0.85 \%$ and $0.90 \%$, respectively. In multivariate model 2, adjusted for baseline HbA1c and sex, significant increase $(0.84 \%)$ was noted in $\mathrm{HbA} 1 \mathrm{c}$ only for AL progression.

\section{DISCUSSION}

The present cohort study assessed associations between periodontal disease and changes in $\mathrm{HbA} 1 \mathrm{c}$ levels in patients with DM. It was observed that periodontal status at baseline and progression of periodontal AL were able to predict changes in HbA1c levels. Specifically, worst glycemic control was observed over time in patients with DM with severe periodontitis at baseline and with clinical AL progression of $\geq 2 \mathrm{~mm}$ in at least one tooth.

Length of follow-up in studies evaluating the relationship between periodontitis and DM varies greatly, reflecting differences among studies. In the present study, average follow-up was 38 months. Studies evaluating influence of periodontitis on glycemic control in patients with DMt2 ranged from 2 to 15 years. ${ }^{11,12,15-17}$ These variations in methodology often occur because there is no standardized method of designing these types of studies, possibly because the temporal relationship between periodontal disease and DM is still not completely understood. ${ }^{16}$

In the present study, females outnumbered males. It has been reported that women are more concerned about their health than men. ${ }^{29}$ It is possible that this finding may be applicable to the present study because greater increase in HbA1c levels was observed in males $(2.75 \%)$ compared with females $(1.20 \%)$, although females presented higher $\mathrm{HbA} 1 \mathrm{c}$ mean levels at baseline compared with males $(7.3 \%$ versus 


\section{Table 2.}

\section{HbA1c Level at Baseline and Its Change Over Time (final to baseline) According to Participant Characteristics}

\begin{tabular}{|c|c|c|c|c|}
\hline Characteristic & Baseline $\mathrm{HbAlc}(\%)$ & $P$ Value & HbAlc Change (\%) & $P$ Value \\
\hline \multicolumn{5}{|l|}{ Age } \\
\hline$<60$ years & 7.24 (6.70 to 7.79$)$ & & $1.70(1.04$ to 2.36$)$ & \\
\hline$\geq 60$ years & 6.58 (6.17 to 7.00$)$ & 0.10 & $1.78(1.03$ to 2.53$)$ & 0.88 \\
\hline \multicolumn{5}{|l|}{ Sex } \\
\hline Males & $6.42(5.94$ to 6.91$)$ & & 2.75 ( 1.72 to 3.78$)$ & \\
\hline Females & $7.30(6.79$ to 7.81$)$ & 0.03 & $1.20(0.71$ to 1.70$)$ & 0.003 \\
\hline \multicolumn{5}{|c|}{ Duration of DM } \\
\hline$\leq 5$ years & 6.53 (5.94 to 7.08$)$ & & 1.88 (0.97 to 2.78$)$ & \\
\hline$>5$ years & 7.34 (6.82 to 7.84$)$ & 0.04 & 1.64 (1.04 to 2.23$)$ & 0.64 \\
\hline \multicolumn{5}{|c|}{ Baseline $\mathrm{HbAIC}$} \\
\hline$<6.5$ & 5.65 (5.46 to 5.83$)$ & & $3.08(2.47$ to 3.69$)$ & \\
\hline$\geq 6.5$ & 8.17 (7.72 to 8.62$)$ & $<0.001$ & $0.57(0.01$ to 1.12$)$ & $<0.001$ \\
\hline \multicolumn{5}{|c|}{ Severe periodontitis at baseline } \\
\hline Yes & $6.92(6.21$ to 7.62$)$ & & $2.32(1.50$ to 3.15$)$ & \\
\hline No & $7.06(6.61$ to 7.51$)$ & 0.72 & $1.37(0.67$ to 1.95$)$ & 0.04 \\
\hline \multicolumn{5}{|c|}{ Progression of $A L \geq 2 \mathrm{~mm}$ over time } \\
\hline$\geq$ tooth & $6.82(6.32$ to 7.31$)$ & & 2.24 (1.56 to 2.91$)$ & \\
\hline 0 teeth & 7.28 (6.66 to 7.89$)$ & 0.24 & $1.00(0.34$ to 1.67$)$ & 0.01 \\
\hline \multicolumn{5}{|c|}{ Tooth loss over time } \\
\hline 0 teeth & $6.97(5.52$ to 7.41$)$ & & $1.63(1.03$ to 2.23$)$ & \\
\hline$\geq 1$ tooth & 7.05 (6.37 to 7.73$)$ & & $1.87(1.00$ to 2.73$)$ & \\
\hline Total & $7.00(6.62$ to 7.38$)$ & 0.82 & 1.73 (1.24 to 2.22$)$ & 0.63 \\
\hline
\end{tabular}

HbA1c baseline and change values are given as mean (95\% confidence interval).

Table 3.

\section{Univariable and Multivariable Models for Changes in HbA1c Level Over Time}

\begin{tabular}{|c|c|c|c|c|c|c|}
\hline \multirow[b]{2}{*}{ Characteristic } & \multicolumn{2}{|c|}{ Univariable (\%) } & \multicolumn{2}{|c|}{$\begin{array}{c}\text { Multivariable I (adjusted for } \\
\text { baseline } \mathrm{HbA} \mid \mathrm{c})(\%)\end{array}$} & \multicolumn{2}{|c|}{$\begin{array}{l}\text { Multivariable } 2 \text { (adjusted for } \\
\text { sex and baseline } \mathrm{HbAlc} \text { ) (\%) }\end{array}$} \\
\hline & $\beta(95 \% \mathrm{Cl})$ & $P$ Value & $\beta(95 \% \mathrm{Cl})$ & $P$ Value & $\beta(95 \% \mathrm{Cl})$ & $P$ Value \\
\hline \multicolumn{7}{|c|}{ Severe periodontitis at baseline } \\
\hline No & Reference & & Reference & & Reference & \\
\hline Yes & 0.95 (0.05 to 1.85$)$ & 0.04 & 0.85 (0.02 to 1.67$)$ & 0.04 & $0.66(-0.19$ to 1.50$)$ & 0.13 \\
\hline 0 teeth & Reference & & Reference & & Reference & \\
\hline$\geq$ I tooth & $1.23(0.26$ to 2.20$)$ & 0.01 & $0.90(0.10$ to 1.72$)$ & 0.03 & 0.84 (0.04 to 1.64$)$ & 0.04 \\
\hline
\end{tabular}

$\mathrm{CI}=$ confidence interval

$6.3 \%$, respectively). Desvarieux et al. ${ }^{30}$ also observed greater association between periodontitis and atherosclerosis, a common DM complication, in males compared with females. It is important to highlight that effect of sex on glycemic control of the present sample was considered in associations between periodontal disease and changes in HbA1c levels by applying multivariable models. One model was adjusted for HbA1c levels at baseline, whereas another model was also adjusted for sex. After adjustment for sex, there was no association between periodontal status at baseline and changes in HbA1c levels. However, progression of 
AL over time still remained significantly associated with changes in HbA1c levels. It is noteworthy that sex predilection is still contradictory in the literature, with other studies showing greater association between periodontitis and DM in females. ${ }^{11,16}$

It is widely known that randomized controlled trials (RCTs) are the best study design to evaluate the relationship between periodontal disease and DM. Studies have shown that significant improvement in glycemic levels can be achieved after periodontal therapy. ${ }^{6,7}$ However, owing to methodologic limitations of the RCTs published, including sample size issues, inclusion criteria, baseline patient characteristics, periodontal therapy outcomes, and biases associated with criteria used to define periodontitis, this relationship is still not clear. ${ }^{31,32}$ Therefore, observational studies are necessary to help identify possible risk factors and predictors for changes in HbA1c levels in patients with DM, although their strength of evidence is lower than that of RCTs. ${ }^{33,34}$

Only a small number of longitudinal studies have compared progression of periodontitis and HbA1c levels. ${ }^{11,12,15,16}$ Some studies evaluated patients with periodontitis but without DM and reported a gradual increase in their HbA1c levels. ${ }^{11,15,16}$ A cohort study with 5-year follow-up evaluated 2,973 patients without DM who were distributed into five groups (healthy, edentulous, and $\mathrm{AL}>5 \mathrm{~mm}$ divided into three groups based on number of teeth involved). HbA1c levels increased through follow-up years in those patients presenting a worse periodontal condition. Authors of the cohort study concluded that a worsening in $\mathrm{HbA} 1 \mathrm{c}$ levels was related to a declining periodontal condition. ${ }^{15}$ Another study evaluated 9,296 dentate and edentulous patients without DM, from the first National Health and Nutrition Examination Survey, with and without periodontal disease, who were followed for 10 to 20 years. Increase in incidence of DM by $50 \%$ was observed in those patients with periodontitis compared with patients without periodontitis at baseline. ${ }^{16}$ Another study followed 5,848 patients without DM for 7 years and found no apparent association between periodontitis and DM incidence, although a tendency for increase in risk was noted. ${ }^{11}$ It is important to emphasize that in the present study patients were required to have at least 24 months between examinations. Thirty patients presented severe periodontitis at baseline and were referred for periodontal treatment, as were others presenting mild or moderate periodontitis. However, none of them followed the recommended treatment or did not have the chance to be treated because of overcrowding in the public health clinics. This has allowed long-term evaluation of their periodontal status.

Other studies have demonstrated a relationship between periodontitis progression as a risk factor for larger changes in glycemic control and other complications associated with DMt2. ${ }^{12,17}$ In a longitudinal study with 2-year follow-up of a Native American population with high incidence of DMt2, it was observed that presence of severe periodontitis (radiographic bone loss $>50 \%$ or $\mathrm{AL}>6 \mathrm{~mm}$ in at least one tooth) at baseline increased risk for high levels of HbA1c. ${ }^{12}$ A more recent study evaluating 5,885 Taiwanese patients during a 5-year period showed that presence of periodontal PD $>4 \mathrm{~mm}$ was associated with a 33\% increase in risk for hyperglycemia, even after adjusting for confounding factors. ${ }^{17}$ In Pima Indians, it was observed that severe periodontitis increased risk for mortality from ischemic heart disease and diabetic nephropathy, ${ }^{13}$ and the effect of periodontal disease on these diseases is in addition to effects of traditional risk factors, such as age, sex, hypertension, and serum cholesterol levels, among others. ${ }^{13}$ Association among periodontal disease severity and nephropathy and end-stage renal disease was also observed, suggesting that periodontal treatment may reduce risk for diabetic renal disease development. ${ }^{14}$

$\mathrm{PD}$ and $\mathrm{AL}$ were used to evaluate the association between periodontal disease and its progression with DM in the present study. Periodontal disease at baseline was classified according to CDC/AAP classification, which is the recommended epidemiologic classification of periodontal disease. ${ }^{27}$ Regarding periodontal disease progression, change in $\mathrm{AL} \geq 2 \mathrm{~mm}$ in at least one tooth was applied for evaluation of periodontal breakdown over the follow-up period. Establishment of appropriate criteria to define periodontal disease progression is more controversial than for definition of periodontal disease status at a certin time point. In this study, a threshold of $2 \mathrm{~mm}$ was applied, as it is widely used in the literature for longitudinal studies. ${ }^{35,36}$ Using this criterion for periodontal progression, a significant increase was observed in levels of $\mathrm{HbA} 1 \mathrm{c}$ after an average of 3 years in patients showing progression of periodontal disease, even after adjusting for $\mathrm{HbA} 1 \mathrm{c}$ levels and sex. These findings are in agreement with the European Federation of Periodontology and the AAP, which suggest that periodontal disease adversely affects glycemic control and DM complications or promotes development of DMt2..$^{9}$ Results also corroborate those from other studies. ${ }^{12,15,17}$

An important finding of this study is augmentation of HbA1c levels of $2.32 \%$ and $2.24 \%$ in patients presenting severe periodontitis at baseline and in those demonstrating periodontal AL progression, respectively. Increases certainly may lead to relevant negative impacts on systemic health due to higher risk for major DM complications. Landmark longitudinal studies in patients with DMt2 have shown evident impact of improvement of $\mathrm{HbA} 1 \mathrm{c}$ levels on risk of microvascular and macrovascular outcomes. ${ }^{37,38} \mathrm{~A}$ decrease of $1 \%$ in 
HbA1c levels was associated with risk reduction in diabetic eye disease and diabetic nephropathy. ${ }^{39}$

In this study, the whole sample showed elevation of $1.73 \%$ in $\mathrm{HbA} 1 \mathrm{c}$ levels, demonstrating that even with use of antidiabetic medication these patients were unable to properly control their glycemic levels on average. It is noteworthy that a more pronounced increase in HbA1c levels of $3.08 \%$ was observed in patients with controlled DM at baseline compared with those with uncontrolled DM. This finding may be due to differences in duration of DM between those with controlled and those with uncontrolled DM at the beginning of the study $(5.5 \pm 0.6$ and $7.5 \pm 0.7$ years, respectively), despite no difference in age between them. It has also been found that patients with $>5$ years of DM duration presented higher baseline HbA1c levels than ones with shorter duration. Over the follow-up period, patients with controlled DM increased their duration of DM. Once microvascular and macrovascular complications increase with duration of $\mathrm{DM},{ }^{40}$ it is suggested that they would present such complications, being more susceptible to risk factors associated with DM control, and also experience an increase in glycemic levels, reaching those of patients with DM for a longer time.

This study has demonstrated association between periodontal disease and worsening of HbA1c levels. These results support the important role the periodontist has in management of DMt2, with treatment as well as making patients aware of the role of periodontal infection in glycemic control. Lalla et al. ${ }^{41}$ assessed an approach applied to patients with potential DM or pre-DM, where the control group received information on DM risk factors and blood test results and were advised to see a physician, whereas test group patients received more detailed explanation on their condition, a written report for the physician, and follow-up contact to inquire about medical followup. After 6 months, patients in the test group presented a significant reduction in $\mathrm{HbA} 1 \mathrm{c}$ levels, and the authors concluded that DM risk assessment and education by dental professionals may contribute to improved patient outcomes. ${ }^{41}$

Findings of the present study should be viewed considering its limitations and strengths. One methodologic limitation of this study was the partial recording protocol used to record $\mathrm{AL}$, which was assessed only in sites with GR. Nevertheless, this approach has clinical implications as it is frequently used by general practitioners who are not used to measuring clinical AL. Another limitation is the possible occurrence of changes in diabetic medication over the follow-up period. This aspect was controlled by including in the study only those patients who were using these drugs both at baseline and during follow-up, although any change in dosages could not be controlled. Anti-infective agents could also be used over the study period, but this probably occurred at random in the whole sample and may have small effects in the findings. Patients might have experienced some adverse effects of DM such as hypertension, but no other major systemic condition was diagnosed or reported in medical charts. The fact that patients were not radiographically examined for chronic apical lesions is also a limitation. Inflammatory mediators released in periapical inflammation are associated with development of insulin resistance, ${ }^{42}$ which may affect metabolic control of patients with DM. ${ }^{43}$ A recent cross-sectional study revealed significantly higher prevalence of apical periodontitis in patients with DMt2 with HbA1c levels $\geq 6.5 \%$, and multivariate analysis demonstrated significant association between periapical status of root-filled teeth and HbA1c levels. ${ }^{44}$ Among the strengths of the study, its longitudinal characteristic and medium-term follow-up period are noteworthy. The sample was homogeneous, consisting of individuals from the same socioeconomic class and environment. Also, the sample was carefully defined, applying important inclusion/exclusion criteria to avoid bias in studied associations, such as exclusion of smokers. Confounding was also controlled using multivariable models, which is essential for study of causal associations.

\section{CONCLUSIONS}

Periodontal disease progression was demonstrated to be associated with an increase in HbA1c levels in patients with DMt2 over 2 years, suggesting that continuing periodontal breakdown parallels worst DM control. Moreover, patients with an initial diagnosis of severe periodontitis had a higher increase in HbA1c levels over time than those without severe periodontitis; however, this association was no longer significant when sex was considered, indicating that sex may modify this association.

Although there is no clear cause-effect relationship between periodontitis and worse glycemic control, identification of periodontal status as risk factor suggests that periodontal treatment may improve glycemic control of patients with DMt2. This information should be taken into consideration when designing future clinical trials and in clinical practice.

\section{ACKNOWLEDGMENTS}

This study was sponsored by grants from the Brazilian Research Agencies: Coordination for the Improvement of Higher Education Personnel (grant nos. PROCAD NF 2313/2008, PROCAD NF 2341/2008, and Estagio Senior 99999.00246/2015-03), Brasilia, DF, Brazil, and the Ceara State Scientific and Technological 
Foundation (grant no. 266.0100/09), Fortaleza, CE, Brazil. The authors report no conflicts of interest related to this study.

\section{REFERENCES}

1. International Federation of Diabetes. The global picture. In: IDF Diabetes Atlas. Belgium: IDF; 2015:47-66.

2. Centers for Disease Control and Prevention. Diabetes Public Health Resource. Available at: http://www.cdc. gov/diabetes/statistics/prev/national/figpersons.htm. Accessed January 4, 2016.

3. Iser BPM, Stopa SR, Chueiri PS, et al. Prevalence of selfreported diabetes in Brazil: Results of the 2013 National Health Survey (in Portuguese). Epidemiol Serv Saúde 2015;24:305-314.

4. Chávarry NG, Vettore MV, Sansone C, Sheiham A. The relationship between diabetes mellitus and destructive periodontal disease: A meta-analysis. Oral Health Prev Dent 2009;7:107-127.

5. Garcia D, Tarima S, Okunseri C. Periodontitis and glycemic control in diabetes: NHANES 2009 to 2012. J Periodontol 2015;86:499-506.

6. Simpson TC, Weldon JC, Worthington HV, et al. Treatment of periodontal disease for glycaemic control in people with diabetes mellitus. Cochrane Database Syst Rev 2015;11:CD004714.

7. Engebretson S, Kocher T. Evidence that periodontal treatment improves diabetes outcomes: A systematic review and meta-analysis. JPeriodontol2013;84(Suppl. 4):S153-S169.

8. Taylor JJ, Preshaw PM, Lalla E. A review of the evidence for pathogenic mechanisms that may link periodontitis and diabetes. J Periodontol 2013;84 (Suppl. 4):S113-S134.

9. Borgnakke WS, Ylöstalo PV, Taylor GW, Genco RJ. Effect of periodontal disease on diabetes: Systematic review of epidemiologic observational evidence. J Periodontol 2013;84(Suppl. 4):S135-S152.

10. Lalla E, Papapanou PN. Diabetes mellitus and periodontitis: A tale of two common interrelated diseases. Nat Reu Endocrinol 2011;7:738-748.

11. Ide R, Hoshuyama T, Wilson D, Takahashi K, Higashi T. Periodontal disease and incident diabetes: A sevenyear study. J Dent Res 2011;90:41-46.

12. Taylor GW, Burt BA, Becker MP, et al. Severe periodontitis and risk for poor glycemic control in patients with non-insulin-dependent diabetes mellitus. J Periodontol 1996;67(Suppl. 10):1085-1093.

13. Saremi A, Nelson RG, Tulloch-Reid M, et al. Periodontal disease and mortality in type 2 diabetes. Diabetes Care 2005;28:27-32.

14. Shultis WA, Weil EJ, Looker HC, et al. Effect of periodontitis on overt nephropathy and end-stage renal disease in type 2 diabetes. Diabetes Care 2007;30: 306-311.

15. Demmer RT, Desvarieux M, Holtfreter B, et al. Periodontal status and A1C change: Longitudinal results from the study of health in Pomerania (SHIP). Diabetes Care 2010;33:1037-1043.

16. Demmer RT, Jacobs DR Jr., Desvarieux M. Periodontal disease and incident type 2 diabetes: Results from the First National Health and Nutrition Examination Survey and its epidemiologic follow-up study. Diabetes Care 2008;31:1373-1379.

17. Chiu SY, Lai H, Yen AM, Fann JC, Chen LS, Chen HH. Temporal sequence of the bidirectional relationship between hyperglycemia and periodontal disease: A community-based study of 5,885 Taiwanese aged 35-44 years (KCIS No. 32). Acta Diabetol 2015;52: 123-131.

18. Costa FO, Miranda Cota LO, Pereira Lages EJ, et al. Progression of periodontitis and tooth loss associated with glycemic control in individuals undergoing periodontal maintenance therapy: A 5-year follow-up study. J Periodontol 2013;84:595-605.

19. Almeida Abdo J, Cirano FR, Casati MZ, et al. Influence of dyslipidemia and diabetes mellitus on chronic periodontal disease. J Periodontol 2013;84:1401-1408.

20. Novaes AB Jr., Gutierrez FG, Novaes AB. Periodontal disease progression in type II non-insulin-dependent diabetes mellitus patients (NIDDM). Part I - Probing pocket depth and clinical attachment. Braz Dent J 1996;7:65-73.

21. Brazilian Institute of Geography and Statistics (in Portuguese). Available at: http://cidades.ibge.gov.br/ xtras/perfil.php?lang=_EN\&codmun=231290\&search= ceara|sobral. Accessed March 3, 2016.

22. Rego RO, Costa KL, Lima V, Susin C, Montenegro RM Jr. Periodontal diseases and type 2 diabetes in Northeastern Brazil. J Dent Res 2010;89(Spec. Issue B): 1113(IADR).

23. Tsai C, Hayes C, Taylor GW. Glycemic control of type 2 diabetes and severe periodontal disease in the US adult population. Community Dent Oral Epidemiol 2002;30: 182-192.

24. Soskolne WA, Klinger A. The relationship between periodontal diseases and diabetes: An overview. Ann Periodontol 2001;6:91-98.

25. Jansson H, Lindholm E, Lindh C, Groop L, Bratthall G. Type 2 diabetes and risk for periodontal disease: A role for dental health awareness. J Clin Periodontol 2006; 33:408-414

26. Rydén L, Grant PJ, Anker SD, et al; Authors/Task Force Members; ESC Committee for Practice Guidelines (CPG); Document Reviewers. ESC Guidelines on diabetes, pre-diabetes, and cardiovascular diseases developed in collaboration with the EASD: The Task Force on diabetes, pre-diabetes, and cardiovascular diseases of the European Society of Cardiology (ESC) and developed in collaboration with the European Association for the Study of Diabetes (EASD). Eur Heart J 2013;34:3035-3087.

27. Eke PI, Page RC, Wei L, Thornton-Evans G, Genco RJ. Update of the case definitions for population-based surveillance of periodontitis. J Periodontol 2012;83: 1449-1454.

28. Hosmer D, Lemeshow S. Applied Logistic Regression, 2nd ed. New York: John Wiley \& Sons; 2000:260-287.

29. Krämer HU, Rüter G, Schöttker B, et al. Gender differences in healthcare utilization of patients with diabetes. Am J Manag Care 2012;18:362-369.

30. Desvarieux M, Schwahn C, Völzke H, et al. Gender differences in the relationship between periodontal disease, tooth loss, and atherosclerosis. Stroke 2004; 35:2029-2035.

31. Borgnakke WS, Chapple IL, Genco RJ, et al. The multicenter randomized controlled trial (RCT) published by the journal of the American Medical Association (JAMA) on the effect of periodontal therapy on glycated hemoglobin (HbA1c) has fundamental problems. J Evid Based Dent Pract 2014;14:127-132.

32. Faggion CM Jr., Cullinan MP, Atieh M. An overview of systematic reviews on the effectiveness of periodontal treatment to improve glycaemic control [published 
online ahead of print February 23, 2016]. J Periodontal Res. 10.1111/jre.12358.

33. Hujoel P. Grading the evidence: The core of EBD. JEvid Based Dent Pract 2009;9:122-124.

34. Niederman R, Richards D. What is evidence-based dentistry, and do oral infections increase systemic morbidity or mortality? Oral Maxillofac Surg Clin North Am 2011;23:491-496, v.

35. Schätzle $M$, Löe $H$, Lang NP, et al. Clinical course of chronic periodontitis. III. Patterns, variations and risks of attachment loss. J Clin Periodontol 2003;30:909918.

36. Teles R, Benecha HK, Preisser JS, et al. Modelling changes in clinical attachment loss to classify periodontal disease progression. J Clin Periodontol 2016; 43:426-434.

37. Stratton IM, Adler AI, Neil HA, et al. Association of glycaemia with macrovascular and microvascular complications of type 2 diabetes (UKPDS 35): Prospective observational study. BMJ 2000;321:405412.

38. Holman RR, Paul SK, Bethel MA, Matthews DR, Neil HA. 10-year follow-up of intensive glucose control in type 2 diabetes. N Engl J Med 2008;359:1577-1589.

39. American Diabetes Association. Implications of the United Kingdom Prospective Diabetes Study. Diabetes Care 2002;25:s28-s32.

40. Zoungas S, Woodward M, Li Q, et al; ADVANCE Collaborative group. Impact of age, age at diagnosis and duration of diabetes on the risk of macrovascular and microvascular complications and death in type 2 diabetes. Diabetologia 2014;57:2465-2474.

41. Lalla E, Cheng B, Kunzel C, Burkett S, Ferraro A, Lamster IB. Six-month outcomes in dental patients identified with hyperglycaemia: A randomized clinical trial. J Clin Periodontol 2015;42:228-235.

42. Astolphi RD, Curbete MM, Chiba FY, et al. Periapical lesions decrease insulin signaling in rat skeletal muscle. J Endod 2015;41:1305-1310.

43. Schulze A, Schönauer M, Busse M. Sudden improvement of insulin sensitivity related to an endodontic treatment. J Periodontol 2007;78:2380-2384.

44. Sánchez-Domínguez B, López-López J, Jané-Salas E, Castellanos-Cosano L, Velasco-Ortega E, SeguraEgea JJ. Glycated hemoglobin levels and prevalence of apical periodontitis in type 2 diabetic patients. J Endod 2015;41:601-606.

Correspondence: Dr. Rodrigo Otavio Rego, Department of Dentistry, School of Dentistry at Sobral, Federal University of Ceara, Rua Estanislau Frota S/N, Sobral, CE, 62010560, Brazil. Fax: 55/88-36132603; e-mail: rodrigorego@ yahoo.com.

Submitted March 5, 2016; accepted for publication July 19, 2016. 